\title{
Effects of Video Modeling on Technical Performance While Teaching Back Stroke Style for the Beginners in Swimming
}

\author{
Manal Gwida Abo Al-Magd ${ }^{1}$
}

${ }^{1}$ Assistant Professor at the Aquatic Sports Department, Faculty of Physical Education, Tanta University, Egypt

\begin{abstract}
The current research aims to identify the effectiveness of an educational program based on video modeling to improve the optimum performance level of back strike for beginner swimmers. The researcher used the experimental approach (two-group design) with pre- and post-measurements. Participants $(n=16)$ were purposefully chosen from beginner swimmers of Tanta Sports club. They were divided into two equivalent groups (experimental/control) with (8) swimmers in each group. Another (12) beginner swimmers from the same research community and outside the main sample was chosen as a pilot sample. Results indicated that the video modeling program had positive effects on the technical performance level of back stroke for beginner swimmers of the experimental group I favor of the post-measurements. There are statistically significant differences on $P \leq 0.05$ between the pre- and post-measurements of the technical performance of back stroke for the experimental group as $(t)$ calculated value (20.97) was higher than its table value and improvement percentage reached $(27.51 \%)$ in favor the post-measurements. There are statistically significant differences on $P \leq 0.05$ between the pre-and post-measurements of the technical performance of back stroke for the control group as (t) calculated value (6.39) was higher than its table value and improvement percentage reached (7.27\%) in favor of the post-measurements. There are statistically significant differences on $P \leq 0.05$ between the post-measurements of the technical performance of back stroke for the experimental and control groups as (t) calculated value (9.97) was higher than its table value and improvement percentage was (20.24\%) in favor of the experimental group.
\end{abstract}

Key words: back stroke - video modeling - beginners

\section{Introduction}

wimming is characterized by complex skills that need a higher degree of neuromuscular coordination among all body parts during motor performance. This requires a balanced distribution of force over all parts involved in motion to move forward in a coordinated way. Resultant forces of arm strokes and leg kicks generated synchronously are added together and the horizontal level of the body in water. This can only be achieved through controlling both the musculoskeletal and nervous systems simultaneously.

Nour, S. (2011) and Abo al-Magd, M. (2007) agreed that technical analysis of the back stroke should highlight five main points affecting optimum performance. These are body position, leg kicks, arm strokes, breathing and coordination. (12) (2)

Abd El-Fattah, A. (2012) indicated that motor perception requires a high degree of coordination so as to show suitable motor behaviors during specific circumstances according to previous experiences and mastered skills.(1)

The researcher thinks that technical errors of back stroke are clear in major points affecting performance. This is consistent with Nour, S. (2011) and Abo al-Magd, M. (2007).(12) (2)
Salem, W. (2000) stated that educational technologies have various positive effects on learning skills, correcting errors and improving performance. The main objective of educational technologies is to enhance he educational process through design, application and evaluation. (13)

Miltenberger, R. (1997) and Grant \& Evans (1994) indicated that modeling is one of the most important procedures used improving athletic performance. It represents a curative procedure and very powerful tool for learning previously acquired skills. It provides the opportunity to perform new responses without errors in addition to being an effective tool for teaching skills and preparing academic activities. (11) (7)

Dowrick, P. (1991) indicated that modeling has various types including exact and behavior-featured imitation, generalized imitation, peer modeling, self-modeling and video modeling. This last type is a type of learning by observation as the model is being recorded by a camera to modify the existing technical performance and teaching new skills. Learners are required to watch videos including optimum performance and then model this performance through imitation until they reach a good degree of efficiency in performance. (6)

Sarafino (2000) and Masia \& Chase (1997) indicated that video modeling is characterized by a high degree of 
controlling performance stimuli. In addition, it is wellbuilt to help individuals act well as it provides learners with sufficient information about how to perform the skill correctly, the right time for performance and the consequences of performance. Furthermore, video modeling is a very special stimulus that affects later performance of the individual. (14) (10)

Lasater \& Brady (1995) agreed that video modeling attracted the attention of researchers interested in improving athletic skills as it is very effective in teaching, generalizing and correcting skills quickly with minimal cost of time and effort. Video modeling led to clear flexibility in teaching several skills and behavior based on imitating video clips as these clips are easy-to use by instructors and athletes to learn skills.(9)

Abd El-Fattah, A. (2012) indicated that it is useful for coaches to recognize the nature of competitive style and to identify the optimum performance and then to compare it with real performance of the athlete to design the training program accordingly with the aim of improving weaknesses until all optimum performance indicators are achieved as closely as possible. (1)

Swimming is characterized by complex performance. Unlike other sports, the aquatic medium hinders swimmers from seeing their errors and this makes them hard to correct. Therefore, coaches/instructors represent the swimmer's eyes to see these errors and correct them. The researcher formulated this research problem in the following question: can video modeling lead beginner swimmers to optimum performance in back stroke?

\section{Aim}

The current research aims to identify the effectiveness of an educational program based on video modeling to

Table 1

Descriptive data and data normality for all participants $(n=16)$

\begin{tabular}{|c|c|c|c|c|c|c|c|}
\hline \multicolumn{2}{|c|}{ Variables } & Measurement & Mean & Median & SD & Flatness & Squewness \\
\hline \multicolumn{8}{|c|}{ Growth Factors } \\
\hline \multicolumn{2}{|c|}{ Age } & Year/month & 10.47 & 10.55 & 0.39 & -1.48 & -0.19 \\
\hline \multicolumn{2}{|c|}{ Height } & $\mathrm{Cm}$ & 148.13 & 147.50 & 5.63 & -0.93 & 0.41 \\
\hline \multicolumn{2}{|c|}{ Weight } & $\mathrm{Kg}$ & 46.38 & 46.00 & 4.94 & 0.51 & 0.23 \\
\hline \multicolumn{8}{|c|}{ Physical abilities } \\
\hline \multirow[t]{2}{*}{ Strength } & Back & $\mathrm{Kg}$ & 51.44 & 50.00 & 5.37 & -0.75 & 0.80 \\
\hline & Legs & $\mathrm{Kg}$ & 73.06 & 75.00 & 6.61 & -0.42 & -0.25 \\
\hline \multicolumn{2}{|c|}{ Shoulder flexibility } & $\mathrm{Cm}$ & 31.94 & 33.50 & 5.53 & -0.24 & -0.55 \\
\hline \multirow[t]{2}{*}{ Instep flexibility } & Flexion & Deg & 18.42 & 18.60 & 0.61 & -1.05 & -0.50 \\
\hline & Extension & Deg & 60.31 & 60.00 & 11.32 & -0.78 & -0.09 \\
\hline \multicolumn{2}{|c|}{ Technical performance } & Deg & 70.69 & 71.00 & 2.41 & -0.65 & -0.43 \\
\hline
\end{tabular}

Table (1) indicated that squewness values ranged between $( \pm 3)$. This indicates the normality of data as it is free of radical distributions. improve the optimum performance level of back strike for beginner swimmers.

\section{Hypotheses}

1. There are statistically significant differences between the pre- and post-measurements of the experimental group on technical performance and the digital record in favor of the post-measurements.

2. There are statistically significant differences between the pre- and post-measurements of the control group on technical performance and the digital record in favor of the post-measurements.

3. There are statistically significant differences between the post-measurements of the experimental and control groups on technical performance and the digital record in favor of the experimental group.

\section{Material and Methods}

\section{Approach:}

The researcher used the experimental approach (two-group design) with pre- and post-measurements.

\section{Participants:}

Participants $(n=16)$ were purposefully chosen from beginner swimmers of Tanta Sports club. They were divided into two equivalent groups (experimental/control) with (8) swimmers in each group. Another (12) beginner swimmers from the same research community and outside the main sample were chosen as a pilot sample. Table (1) shows data normality on all research variables.
The researcher examined both groups to assure that they are equivalent as seen in table (2). 
Table 2

Descriptive data of the research groups $(\mathrm{n} 1=\mathrm{n} 2=8)$

\begin{tabular}{|c|c|c|c|c|c|c|c|c|}
\hline \multirow{2}{*}{\multicolumn{2}{|c|}{ Variables }} & \multirow{2}{*}{ Measurement } & \multicolumn{2}{|c|}{ Experimental } & \multicolumn{2}{|c|}{ Control } & \multirow{2}{*}{ Means difference } & \multirow{2}{*}{$(\mathrm{t})$} \\
\hline & & & Mean & SD & Mean & SD & & \\
\hline \multicolumn{9}{|c|}{ Growth Factors } \\
\hline \multicolumn{2}{|c|}{ Age } & Year/month & 10.36 & 0.34 & 10.58 & 0.43 & 0.21 & 1.10 \\
\hline \multicolumn{2}{|c|}{ Height } & $\mathrm{Cm}$ & 147.63 & 5.83 & 148.63 & 5.78 & 1.00 & 0.34 \\
\hline \multicolumn{2}{|c|}{ Weight } & $\mathrm{Kg}$ & 46.68 & 3.45 & 46.09 & 3.66 & 0.58 & 0.31 \\
\hline \multicolumn{9}{|c|}{ Physical abilities } \\
\hline \multirow{2}{*}{ Strength } & Back & $\mathrm{Kg}$ & 51.63 & 4.88 & 51.25 & 5.35 & 0.38 & 0.14 \\
\hline & Legs & $\mathrm{Kg}$ & 73.50 & 5.37 & 72.63 & 8.02 & 0.88 & 0.26 \\
\hline \multicolumn{2}{|c|}{ Shoulder flexibility } & $\mathrm{Cm}$ & 32.50 & 4.83 & 31.38 & 6.44 & 1.12 & 0.40 \\
\hline \multirow{2}{*}{ Instep flexibility } & Flexion & Deg & 18.31 & 0.61 & 18.53 & 0.63 & 0.21 & 0.69 \\
\hline & Extension & Deg & 61.25 & 13.82 & 59.38 & 9.04 & 1.88 & 0.32 \\
\hline \multicolumn{2}{|c|}{ Technical performance } & Deg & 70.50 & 2.45 & 70.88 & 2.53 & 0.38 & 0.30 \\
\hline
\end{tabular}

(t) Table value on $0.05=1.76$

Table (2) indicated that there are no statistically significant differences between the experimental and control groups on all research variables and $(\mathrm{t})$ table value was higher than its calculated value.

\section{Data Collection Tools:}

1. Medical balance for weights - A Restameter for heights - An electronic dynamometer for strength (legs - back) - A graded ruler for shoulder flexibility - A protractor for instep flexibility - A stop-watch - A camera - A floating board - A bench - A laptop

2. The researcher developed an evaluation form for performance level (annex 1)

Table 3

means differences between the distinguished and non-distinguished groups $(\mathrm{n} 1=\mathrm{n} 2=6)$

\begin{tabular}{|c|c|c|c|c|c|c|c|c|}
\hline \multirow{3}{*}{ Log } & \multicolumn{2}{|c|}{ Distinguished } & \multicolumn{2}{|c|}{ Non-distinguished } & \multirow{2}{*}{ Means difference } & \multirow{2}{*}{$(\mathrm{t})$} & \multirow{2}{*}{ ETA2 } & \multirow{2}{*}{ Validity } \\
\cline { 2 - 11 } & Mean & SD & Mean & SD & & & & \\
\cline { 2 - 11 } & 78.50 & 4.84 & 56.38 & 3.79 & 22.12 & 0.87 & 0.93 \\
\hline
\end{tabular}

(t) Table value on $0.05=1.81$

Effect Size for ETA2: $($ weak $=0$ to $0.30-$ moderate $=0.30$ to $0.50-$ strong $=0.50$ and above $)$

Table (3) indicated statistically significant differences between the means of the distinguished and nondistinguished groups on the evaluation $\log$ in addition to a high degree of effect size. This indicates the validity of the evaluation $\log$.

\section{Reliability of Physical Tests:}

Table 4

Correlation coefficients between test and retest for reliability $(n=12)$

\begin{tabular}{|c|c|c|c|c|c|}
\hline \multirow{3}{*}{ Log } & \multicolumn{2}{|c|}{ Test } & \multicolumn{2}{c|}{ Retest } & \multirow{2}{*}{$\mathrm{R}$} \\
\cline { 2 - 5 } & Mean & SD & Mean & SD & \\
\cline { 2 - 5 } & 67.44 & 6.52 & 68.25 & 5.86 & 0.90 \\
\hline \multicolumn{6}{|c}{ R Table value on $0.05=0.57$}
\end{tabular}

Table (4) indicated statistically significant correlations between test and retest for the evaluation log. This proves the reliability of this $\log$.

\section{The Educational Video Modeling Program:}

This program works on improving the technical performance level of the back stroke using video modeling to reach optimum performance. This general aim leads to the following objectives:

- Understanding the nature of correct back stroke performance.

- Practicing back stroke in a cooperative atmosphere.

- Correcting technical errors of the back stroke performance (body position - head position - leg kicks arm strokes - breathing and general coordination). 


\section{Behavioral objectives:}

All objectives were stated clearly with clear description of the optimum performance and the expected outcomes of the program through fulfilling the conditions of correct performance:

- Technical steps of back stroke.

- Specific drills for correcting errors.

- Designing the program as modules and each module contains videos that model specific skills and drills.

\section{Program Content:}

According to review of literature, several concepts, facts and information related to back stroke were chosen to identify the video modeling for skills under investigations. Video clips were chosen according to motor chains of back stroke. This motor sequence is consistent with the aims of this program aims so that the content becomes:

- Related to program objectives.

- Suitable for experiences, needs and abilities of beginners.

- Continuous and integrated.

\section{Educational Activities (Teaching Strategy) for the Program:}

The program included two types of activities (experimental group) for teachers and learners as follows:

\section{Activities for teachers:}

- Clarifying objectives for beginners.

- Observing beginners during performance to give feedback and correct errors.

- Asking beginners to perform according to gradual steps from simple to complex and from easy to difficult after the end of the program to correct errors and direct beginners towards correct performance.

\section{Activities for Learners:}

- Practicing back stroke and its drills.

- Asking questions about the skill.

\section{Timeframe of Program:}

1. Program lasts for (12) weeks (3 modules per week) with total number of (36) modules .

2. Total duration of the module is (120) minutes allocated as follows:

- Warm up (10 min).
- Video modeling (experimental)/ regular instruction (control) (20 min).

- Main part (70 min).

- Cool down (20 min).

\section{Preparation of Video Modeling:}

The researcher downloaded several video clips concerning back stroke from the internet. These clips were edited and rendered using Cyber link / power direct (v12) software. These clips included all topics to be covered like errors and optimum performance so as to correct mistakes. Clips included illustrations, photos and real videos.

\section{Organizing video content:}

Video modeling is presented via laptop and each clip contains the following:

- Introduction for each part of the back stroke.

- Performance method.

- Common errors in each part.

- Curative drills for correcting mistakes.

\section{Application:}

Video modeling program was applied to the experimental group ( $n=8)$ while the control group $(n=8)$ remained under regular training. Application steps include:

- Presenting the part that needs correction .

- Beginners watch the video .

- Beginners practice the part in water.

- Instructor observes performance and corrects it according to video modeling.

- Beginners watch curative drills and perform it in water.

- Evaluating beginners' learning using the technical performance evaluation log.

\section{Main Study:}

Pre-measurements were taken for all participants from 109-2014 to 12-9-2014. The recommended program (video modeling) (annex 2) was applied to the experimental group while the control group continued its regular training from 15-9-2014 to 15-12-2014. Postmeasurements were performed for all participants from 16-12-2014 to 18-12-2014 using the evaluation log (annex 1). 


\section{Statistical Treatment:}

Mean - SD - median - flatness - squewness - (t) test -

ETA2 - Cohen's equation for effect size - improvement percentage.

Table 5

Statistical Significance between pre- and post-measurements of the experimental group on the technical performance of back stroke $(n=8)$

\begin{tabular}{|c|c|c|c|c|c|c|c|c|c|}
\hline Variable & \multicolumn{2}{|c|}{ Pre- } & \multicolumn{2}{|c|}{ Post- } & \multirow{2}{*}{ (t) } & \multirow{2}{*}{$\begin{array}{c}\text { Improvement } \\
\text { percentage }(\%)\end{array}$} & \multirow{2}{*}{ ETA2 } & \multirow{2}{*}{$\begin{array}{l}\text { Effect } \\
\text { size }\end{array}$} & \multirow{2}{*}{ Significance } \\
\hline Technical performar & Mean & SD & Mean & SD & & & & & \\
\hline back stroke & 70.88 & 2.53 & 90.38 & 2.86 & 20.97 & 27.51 & 0.98 & 4.75 & High \\
\hline
\end{tabular}

(t) Table value on $0.05=1.89$

Effect size significance: low $=0.20-$ moderate $=0.5-$ high $=0.8$

Table (5) indicates statistically significant differences on technical performance of back stroke for the experimental $\mathrm{P} \leq 0.05$ between the pre- and post-measurements of the group in favor of the post measurements.

Table 6

Statistical Significance between pre- and post-measurements of the control group on the technical performance of back stroke $(\mathrm{n}=8)$

\begin{tabular}{|c|c|c|c|c|c|c|c|c|c|}
\hline \multirow{3}{*}{$\begin{array}{c}\text { Variable } \\
\begin{array}{c}\text { Technical performance of } \\
\text { back stroke }\end{array}\end{array}$} & \multicolumn{2}{|c|}{ Pre- } & \multicolumn{2}{|c|}{ Post- } & \multirow{2}{*}{$(\mathrm{t})$} & \multirow{2}{*}{$\begin{array}{c}\text { Improvement } \\
\text { percentage }(\%)\end{array}$} & \multirow{2}{*}{ ETA2 } & \multirow{2}{*}{$\begin{array}{c}\text { Effect } \\
\text { size }\end{array}$} & \multirow{2}{*}{ Significance } \\
\hline & Mean & SD & Mean & SD & & & & & \\
\hline & 70.50 & 2.45 & 75.63 & 2.67 & 6.93 & 7.27 & 0.87 & 0.75 & Moderate \\
\hline
\end{tabular}

(t) Table value on $0.05=1.89$

Effect size significance: low $=0.20-$ moderate $=0.5-$ high $=0.8$

Table (6) indicates statistically significant differences on $\mathrm{P} \leq 0.05$ between the pre- and post-measurements of the technical performance of back stroke for the control group in favor of the post measurements.

Table 7

Statistical Significance between post-measurements of the experimental and control groups on the technical performance of back stroke $(\mathrm{n} 1=\mathrm{n} 2=8)$

\begin{tabular}{|c|c|c|c|c|c|c|c|c|c|}
\hline \multirow{3}{*}{$\begin{array}{c}\text { Variable } \\
\text { Technical performance of } \\
\text { back stroke }\end{array}$} & \multicolumn{2}{|c|}{ Experimental } & \multicolumn{2}{|c|}{ Control } & \multirow{2}{*}{ (t) } & \multirow{2}{*}{$\begin{array}{c}\text { Improvement } \\
\text { percentage }(\%)\end{array}$} & \multirow{2}{*}{ ETA2 } & \multirow{2}{*}{$\begin{array}{c}\text { Effect } \\
\text { size }\end{array}$} & \multirow{2}{*}{ Significance } \\
\hline & Mean & SD & Mean & SD & & & & & \\
\hline & 90.38 & 2.86 & 75.63 & 2.67 & 9.97 & 20.24 & 0.87 & 3.73 & High \\
\hline
\end{tabular}

(t) Table value on $0.05=1.76$

Effect size significance: low $=0.20-$ moderate $=0.5-$ high $=0.8$

Table (7) indicates statistically significant differences on $\mathrm{P} \leq 0.05$ between the post-measurements of the technical performance of back stroke for the experimental and control groups in favor of the experimental group.

\section{Discussion}

Table (5) indicates statistically significant differences on $\mathrm{P} \leq 0.05$ between the pre- and post-measurements of the technical performance of back stroke for the experimental group as (t) calculated value (20.97) was higher than its table value and improvement percentage reached $(27.51 \%)$. the effect size (4.75) was high due to the positive effects of the video modeling program on the technical performance of back stroke for beginners.

The researcher thinks these results are due to the positive effects of the recommended program on improving the technical performance level of back stroke as it helped beginners to perform more accurately through modeling the requirements of the back stroke. The program considered individual differences among participants. This is consistent with several previous studies. (3) (5) (12) (4) (2) (15)

Table (6) indicates statistically significant differences on $\mathrm{P} \leq 0.05$ between the pre- and post-measurements of the technical performance of back stroke for the control group as (t) calculated value (6.39) was higher than its table value and improvement percentage reached $(7.27 \%)$. the effect size (0.75) was moderate due to the regular program used with the control group.

The researcher thinks that these improvements are due to the regular program used with the control group as it contained physical and technical exercises that led to these improvements. In addition, punctuality of participants, time allocated for each unit and time distribution on unit components are all factors related to improvements seen in control group. The content of the program also had positive effects on physical and technical aspects. This is consistent with several previous studies. (12) (4) (2) 
Table (7) indicates statistically significant differences on $\mathrm{P} \leq 0.05$ between the post-measurements of the technical performance of back stroke for the experimental and control groups as (t) calculated value (9.97) was higher than its table value and improvement percentage was (20.24\%). the effect size between the two groups (3.73) was in favor of the experimental group. This high effect size is due to the recommended program applied to the experimental group and its effects on the technical performance level of participants.

The researcher thinks that this superiority of the experimental group over the control group is due to the use of video modeling as a base for designing and planning the content of the recommended program. This is consistent with several previous studies. (3) (5) (4) (2) (15)

To fulfill the general aim of this research, the researcher used video modeling to improve the technical performance level of back stroke for beginners. In addition, the researcher considered growth characteristics and abilities of this age group. All these factors had positive effects on the experimental group. Teaching aids make teaching more positive in addition to increasing the speed of learning. It helps reducing time required to teach a skill. It also illustrates the characteristics of the motor skill accurately for learners and this attracts the attention of learners and improves their performance.

Haywood, K.M. (1993) indicated that there are several ways for understanding the nature of acquiring motor skills and how they happen. The most common way is based on the concept that every human being has his/her own information processing system through which he/she gathers information from the surrounding environment, processes them, prepares a suitable response and then returns this response to the environment as a reaction .(8)

The researcher thinks that video modeling is more effective than the regular model/explanation method used with the control group as video models were previously prepared to represent the fine details of the motor skill in addition to the ability of retraining the skill for several times according to the same correct performance. Therefore, video modeling is an effective strategy for supporting sports performance in general and especially swimming. It is a means through which several skills can be improved on condition that it is used in a well-prepared environment. Video is a modern method for teaching athletes and providing them with sensory experiences. They can track the motor skill visually in addition to improving hand-eye coordination and several activities other than automatic reactions. When the desired response appears it is reinforced through repetitions and other enforcers until the athlete performs the required response without any enforcers.

\section{Conclusions}

In the light of this research aims, hypotheses, methods and results, the researcher concludes the following:

1. The video modeling program had positive effects on the technical performance level of back stroke for beginner swimmers of the experimental group I favor of the postmeasurements.

2. There are statistically significant differences on $\mathrm{P} \leq 0.05$ between the pre- and post-measurements of the technical performance of back stroke for the experimental group as (t) calculated value (20.97) was higher than its table value and improvement percentage reached $(27.51 \%)$ in favor the post-measurements.

3. There are statistically significant differences on $\mathrm{P} \leq 0.05$ between the pre- and post-measurements of the technical performance of back stroke for the control group as (t) calculated value (6.39) was higher than its table value and improvement percentage reached $(7.27 \%)$ in favor of the post-measurements.

4. There are statistically significant differences on $\mathrm{P} \leq 0.05$ between the post-measurements of the technical performance of back stroke for the experimental and control groups as (t) calculated value (9.97) was higher than its table value and improvement percentage was (20.24\%) in favor of the experimental group.

\section{Recommendations}

In the light of this research results and conclusions, the researcher recommends the following:

- Using the recommended video modeling educational program as a means for improving technical performance of back stroke for beginner swimmers .

- Informing swimming coaches and instructors about the recommended program especially in swimming schools in sports clubs and during preparation stage.

\section{References}

1. Abd El-Fattah, Abo Al-Ela A. (2012): Contemporary Sports Training. Dar Al-Fikr Al-Araby - Cairo - Egypt (in Arabic). PP: 58- 233

2. Abo Al-Magd, Manal G. (2007): Effects of Specific exercises on improving the performance of back stroke for swimming blossoms. Journal of Theories and Applications of Physical Education, Vol. 62 - Faculty of Physical 
Education for Men - Alexandria University - Egypt (in Arabic)

3. Cannella-Malone, H. I., Mizrachi, S. B., Sabielny, L. M., \& Jimenez, E. D.: Teaching physical activities to students with significant disabilities using video modeling. Developmental neurorehabilitation, 16 (3), (2013). 145-154.

4. Clark, Shannon E., and Diane M. Ste-Marie.: The impact of self-as-a-model interventions on children's selfregulation of learning and swimming performance. Journal of Sports Sciences 25.5 (2007): 577-586.

5. De Koning, J. J., Foster, C., Lucia, A., Bobbert, M. F., Hettinga, F. J., \& Porcari, J. P.: Using modeling to understand how athletes in different disciplines solve the same problem: Swimming versus running versus speed skating. International journal of sports physiology and performance, 6(2), (2011).276-280.

6. Dowrick, P.: Practical Guide to Using Video in the Behavioral Sciences. New York: John Wiley, 1991.

7. Grant, L. and Evans, A.: Principles of Behavior Analysis New York: Harper Collins , 1994

8. Haywood, K.M. (1993) .Life Span Motor Development, Second Edition, Human Kinetics, 1993. P: 282
9. Lasater, M. W. and Brady, M.P.: Effects of Video Selfmodeling and feedback on task fluency: A home-based intervention. Education and Treatment of Children, 18,389-408, 1995.

10. Masia, C and Chase, P.: Vicarious learning revisited: A contemporary behavior analytic interpretation. Journal of Behavior Therapy and Experimental Psychiatry, 28, 41$51,1997$.

11. Miltenberger, R.: Behavior Modification. Principles and Procedures. Pacific Grove, CA: Brooks/Cole, 1997.

12. Nour, Sherif A. (2011): Effects of a specific exercises program on improving the technical performance and digital record of back stroke for junior swimmers. Master thesis, Faculty of Physical Education- Tanta University Egypt (in Arabic)

13. Salem, Wafika M. (2001): Educational Technology in Physical Education - Part One. Munshaat Al-Maaref Alexandria - Egypt (in Arabic) P: 13

14. Sarafino, E: Behavior Modification: Principles of behavior Change, 2nd ed. McGraw, 2000.

15. Verger, M.: Swimming pre- professional modules in the sciences and techniques in physical education and sport at university level., e. p. s., education physique et sport (Paris) 298, Nov / dec p 3, 2002. 